\title{
Prospects for development of heat supply systems in high-rise districts
}

\author{
Viktor Zhila ${ }^{1}$, Elena Solovyeva $^{1 *}$ \\ ${ }^{1}$ Moscow State University of Civil Engineering, Yaroslavskoe shosse, 26, Moscow, 129337, Russia
}

\begin{abstract}
The article analyzes the main advantages and disadvantages of centralized and decentralized heat supply systems in high-rise districts. The main schemes of centralized heat supply systems are considered. They include centralized heat supply from boiler houses, centralized heat supply from autonomous heat sources, heat supply from roof boiler houses and door-to-door heating supply. For each of these variant, the gas distribution systems are considered and analyzed. These systems vary depending on the heat source location. For each of these systems, technical and economic indicators are taken into account, the analysis of which allows choosing the best option for districts where high-rise buildings predominate.
\end{abstract}

\section{Introduction}

The orientation of the Russian energy sector to district heating and centralized heat supply as the main way to meet the heat needs of cities and industrial centers did not justify itself technically and economically. Performance of district heating and heating systems is improper, there are a lot of unsuccessful technical solutions, unused reserves, which reduce the economy and reliability of these systems. Especially it is necessary to pay attention during heat supply of high-rise buildings.

The industrial character of the structure of district heating systems (DHS) with combined heat and power plant (CHP) and boiler houses, the groundlessness of the scale of onsumers connection and the practical uncontrollability of the operating modes of the DHS (sources - heating networks - consumers) have largely devalued the advantages of centralized heat supply. If the sources of thermal energy are still comparable with the world level, the analysis of the DHS shows the following

- The technical equipment and the level of technological solutions for the construction of heat networks correspond to the state of the 1960s, while the radii of heat supply increased sharply, and a change to the new standard sizes of pipe diameters took place;

- The quality of the metal heat pipes, heat insulation, shutoff and control valves, construction is much inferior to foreign analogues, which leads to large losses of thermal energy in the networks;

\footnotetext{
*Corresponding author solovyva@mail.ru
} 
- Poor thermal and water insulation of pipelines and heating network channels increased the damage of underground heat pipes, which led to serious problems of replacing the equipment of heating networks;

- The domestic equipment of large CHP plants corresponds to the average foreign level of the 1980s, and at present steam turbine CHP plants are characterized by high fault rate, as almost half of the installed capacity of turbines has developed a calculated resource;

- There are no flue gas cleaning systems from NOx and SOx at the operating coal-fired CHP plants, and the efficiency of participate trapping often does not reach the required values. These environmental problems affect the living conditions of people who live in high-rise buildings;

- At the present stage competitiveness of the CHP can be ensured only by new technical solutions, both in the structure of systems, and in the schemes, as well as by supplement of energy sources and heat networks.

- It should be mentioned that traditional modes of operation of district heating in practice have the following disadvantages:

- Problems with regulation of heat supply for heating of buildings during transitional periods, when wind, solar radiation, domestic heat release exert a particularly great influence on the thermal conditions of heated rooms;

- Overrun of fuel and over-heating of buildings in the warm periods of the heating season;

- $\quad$ Large heat losses during its transportation (10\% and even more);

- Irrational consumption of electricity for pumping heat carrier, due to the very principle of central quality regulation;

- Long-term operation of the supply pipes of the heating network in an unfavorable temperature regime, characterized by an increase in corrosion processes, etc.

The advantage of centralized heat supply lies in the combined generation of thermal and electrical energy at the CHP plant. The thing is that the increase in the number of autonomous boiler houses will definitely not lead to a decrease in fuel consumption at the CHP plants (provided that the power generation is unchanged) [1]. This indicates that fuel consumption is increasing in the city in general, and the level of air pollution is increasing.

\section{Methods of research}

The modern system of decentralized heat supply represents a complex set of functionally interconnected equipment, including an autonomous heat generating installation and building engineering systems (hot water, heating and ventilation systems).

Recently, many Russian regions are interested in the energy-efficient technology for door-to-door heat supply of multistorey buildings, that is a kind of decentralized heat supply, when each apartment in a multi-family house is equipped with an autonomous system for heat and hot water providing. The main elements of the apartment heating system are the heating boiler, heating appliances, air supply and flue gas systems. Arrangement of pipe-lines is performed using steel pipes or modern piping systems plastic or metal-plastic.

Objective prerequisites for the use of autonomous (decentralized) heat supply systems are:

- The absence in some cases of free capacities on centralized sources;

- Increase in number of housing facilities;

- a significant part of the construction is in the area with undeveloped engineering infrastructure;

- Lower capital investment and the possibility of phased thermal loads; 
- Comfortable conditions in the apartment at one's own will, which in turn is more attractive in comparison with the centralized heat supply, where temperature depends on the directions on the beginning and the end of the heating period;

- The appearance of a large number of different modifications of domestic and imported heat generators of low power on the market.

Heat generators can be placed in the kitchen, in a separate room on any floor (including attic or basement) or in anaddition.

The most common scheme of autonomous (decentralized) heat supply includes: a single-circuit or dual-circuit boiler, circulation pumps for heating and hot water supply, check valves, closed expansion tanks, safety valves. In the case of a single-circuit boiler, a capacitive boiler or plate heat exchanger is used for the preparation of hot water [2].

Advantages of decentralized heat supply are as follows:

- There is no need in land allocation for heating networks and boiler houses;

- Reduction in heat losses due to lack of external heat networks, in network water losses, as well as the reduction in expenses for water treatment;

- Significant reduction in expenses for repair and maintenance of equipment;

- Full automation of consumption modes.

In autonomous heat supply systems it is not recommended to use unprepared water from the water pipe because of its aggressive impact on the boiler elements, which necessitates the use of filters and other water treatment devices.

Increasing the economy of such a system is achieved by using the heat released during the combustion of natural gas as a source of energy.

Door-to-door heat supply is popular in many European and Asian countries. In Russia multistorey buildings with autonomous heat supply have already been built in Smolensk, Serpukhov, Bryansk, St. Petersburg.

Among the experimental buildings built in the Russian regions, there are both high-rise elite and mass building houses. Their price is higher than of houses with centralized heat supply, but the level of comfort gives advantages in the real estate market, because owners of such houses can decide for themselves on the quantity of heat and hot water.

Decentralized systems of any kind allow excluding energy losses during its transportation (as a result, the cost of heat for the end user is reduced), increasing the reliability of heating and hot water supply systems.

Despite all advantages of decentralized heat supply, there are also negative sides. In small boiler houses, including "roof" ones, the height of the chimneys, as a rule, is much lower than for large ones. With the total equal of heat power, the emission values do not change, but the dispersion conditions deteriorate sharply. In addition, small boiler houses are located, as a rule, near a residential area.

However, the impact of large boiler and CHP emissions on different floors of residential buildings is almost the same; because of concentrations leveling in height occurs depending on the remoteness of the pollution source. The height of the pipes of small boiler houses and the height of apartment houses are commensurable, and therefore emissions are carried out practically at the level of the upper floors.

In the fuel balance of municipal heating, natural gas is about $45 \%$. Because of obsolete technologies, gas combustion is approximately 1.5 times greater than required $[3,4]$.

Combustion of natural gas as an environmentally friendly fuel should be as close as possible to the consumer that makes it possible to reduce losses in the thermal energy transport. This can be achieved by autonomous and quarterly heat supply and by use of fundamentally new system of quantitative and qualitative regulation, ensuring the coincidence of the modes of heat generation and consumption with the least losses and costs. 
Autonomous heat supply can be successfully implemented in the construction of new areas, as well as existing areas of mass construction.

In a number of Russian cities (Smolensk, Serpukhov, Nevinnomyssk, Cheboksary, Yakutsk, Belgorod) apartment heating systems are being introduced. But it leads to some problems $[5,6]$ :

- heating of stairwells and cellars;

- allocation, construction and material of chimneys arrangement of gas meters;

- Location of gas pipelines.

The main disadvantages of centralized heat supply systems:

- poor quality of heat networks leads to heat losses $(20 \ldots .25 \%)$;

- high level of costs for operation of heating networks (about 50\% of all costs in heat supply systems);

- high degree of deterioration of heating networks and excess of critical level of failure rate;

- overheating of buildings during the transition period;

- impossibility of consumers (population) to determine the quantity, quality and price of service;

- significant overestimation of heat consumption in residential buildings in comparison with the actual;

- low coverage of residential buildings with heat meters;

- low heat insulation characteristics of residential buildings.

In fact, the population is not a buyer of heat, but only a consumer, it can not control the volume, quality and price of heat energy. It should be noted that the heat supply in Russia have been developed gearing to district heating introduction (combined heat and power generation). Very often, residential areas located near a large industrial hub were supplied with heat from a centralized source. The economic crisis of the last 15 years has led to an industrial recession.

Advantages of autonomous heat supply systems are as follows:

- there is no need to alienate land for construction of a heat source and networks;

- reduction of heat losses due to lack of external heat networks, reduction of network water losses, as well as of costs for water treatment;

- a significant reduction in the cost for equipment repair and maintenance;

- full automation of consumption modes.

\section{Results of research}

The heat supply system includes a source, heat networks, switchgears (IHP-individual heat point, $\mathrm{CHC}$ - central heating center) and a consumer.

One of the variants for decentralized heat supply is boiler stations located on the roof. In this case there are no heat networks, no problems with additional land allocation and installation of a high chimney. In the boiler station located on the roof, lightweight structures with aluminum heat exchangers or copper finned tubes are used. It is possible because of the favorable hydraulic operating conditions of the equipment, because of static pressure lack.

Roof boiler stations provide maintenance of a necessary temperature mode for heating of an individual building.

The technology of the "floating floor" of the boiler room and the installation of vibration compensators on the supply and discharge pipelines, makes it possible to provide noise control and reduce vibration forced by operating equipment. 
Hot-water boilers operating on natural low pressure $(5 \mathrm{kPa})$ gas with a coolant temperature up to $115^{\circ} \mathrm{C}$ is used in roof boiler stations.

Constant presence of maintenance personnel is not needed in boiler stations because of high level of automation.

At buildings heating from roof boiler stations it is possible to support necessary comfortable temperature of air by selection of the individual schedule of temperatures of the water submitted in a heating network.

The roof boiler station works in a mode of $70 \ldots 75 \%$ of the rated capacity in the heating season and in a mode of $25 \%$ in summer. This makes it possible to carry out preventive and repair work with a partial shutdown of thermal capacities in any period [7].

The time for preventive maintenance of roof boiler stations is no more than 3 days. At the same time, with centralized heat supply, the system switches off for 3 weeks.

To reduce the extent of heat networks, autonomous boiler stations are used in the attached construction (directly adjacent to the building).

\section{Discussion}

After the collection of all necessary information, a comparison of four heat supply systems was carried out on the example of the Kurkino district of Moscow. In this case, all apartments are equipped with electric cookers.

Variant 1 - centralized heating from boiler stations.

Variant 2 - centralized heating from autonomous heat sources.

Variant 3 - decentralized heating from boiler stations located on the roof.

Variant 4 - door-to-door heating.

In the variant 1 , a district heating system is developed, where the heat source is a boiler station, from which two pipes are provided for heating networks to the central heating station, and after the central heating station there are four pipes for heating and hot water supply. In this case, the gas is supplied to the boiler station.

In the variant 4 , a local heat source is installed in the apartment, which ensures the supply of heat to the heating and hot water supply systems.

In this scheme, a two-stage gas supply system is proposed:

first stage - medium-pressure gas pipeline, which is laid in the residential district; in each house a cabinet control point is installed;

second stage - low-pressure domestic gas pipelines. Gas is supplied only to a local source of heat.

Variants 2 and 3 are intermediate between variants 1 and 4 . In the second case, autonomous heat sources are used as a source of heat, from which two pipes are laid from autonomous heat sources to individual heat point, and there are four pipes for heating and hot water supply from individual heat point [8].

In this case, gas is supplied to autonomous heat sources via medium-pressure gas pipelines. In the variant 3, a relatively low power (from 300 to $1000 \mathrm{~kW}$ ) boiler station located on the roof is used as a heat source.

The gas pipeline to the boiler station is laid along the outer wall of the building, in places convenient for servicing and excluding the possibility of its damage [9].

Variants of heat supply systems are presented in the Figure 1. 


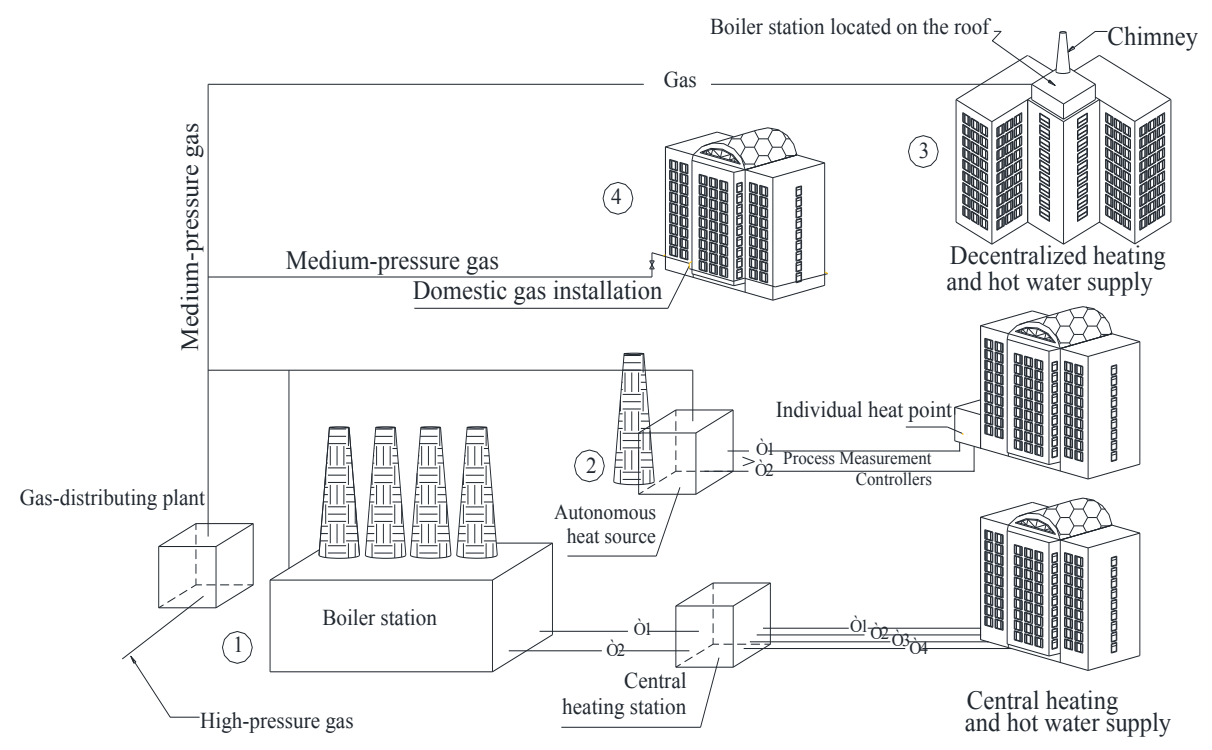

Fig. 1. Schematic diagrams of heat supply systems

Technical solutions for heat supply according to the several variants should be made on the basis of technical and economic calculations. The best variant can be determined by comparing possible solutions [5].

The most expensive variant of heat supply is the variant 1 - centralized heat supply from the boiler station. In this case, a large part of the costs are accounted for heat networks taking into account the central heating station, which is $63.8 \%$ of the total cost of the whole system. Among them, $84.5 \%$ account for the laying of only heat networks. The cost of the heat source is $34.7 \%$, of gas networks accounting for gas-distributing plant and cabinet-type gas control point is $1.6 \%$ of the total amount for the system $[7,10]$.

Variant 4 is only $4.2 \%$ cheaper than the variant 1 (Figure 2). Hence, they can be accepted as interchangeable. If in the variant 1 the most part of the costs are heat networks, then in the variant 4 it belongs to the heat source, i.e. wall boilers $(62.14 \%$ of the total cost of the whole system) [11].

It is worth paying attention to the other two variants: roof boiler stations and autonomous heat sources.

Concerning economics, the variant 2 is more profitable, that is, centralized heat supply from autonomous heat sources. In this variant, the most part of the costs is accounted for heat networks with regard to individual heating station, which is $67.3 \%$ of the total cost of the system. Among them, the heat networks account for $20.3 \%, 79.7 \%$ - individual heating stations. The cost of the heat source is $26 \%$, the share of gas networks, taking into account gas-distributing plant and cabinet-type gas control point is $6.7 \%$ of the total amount of the system. 


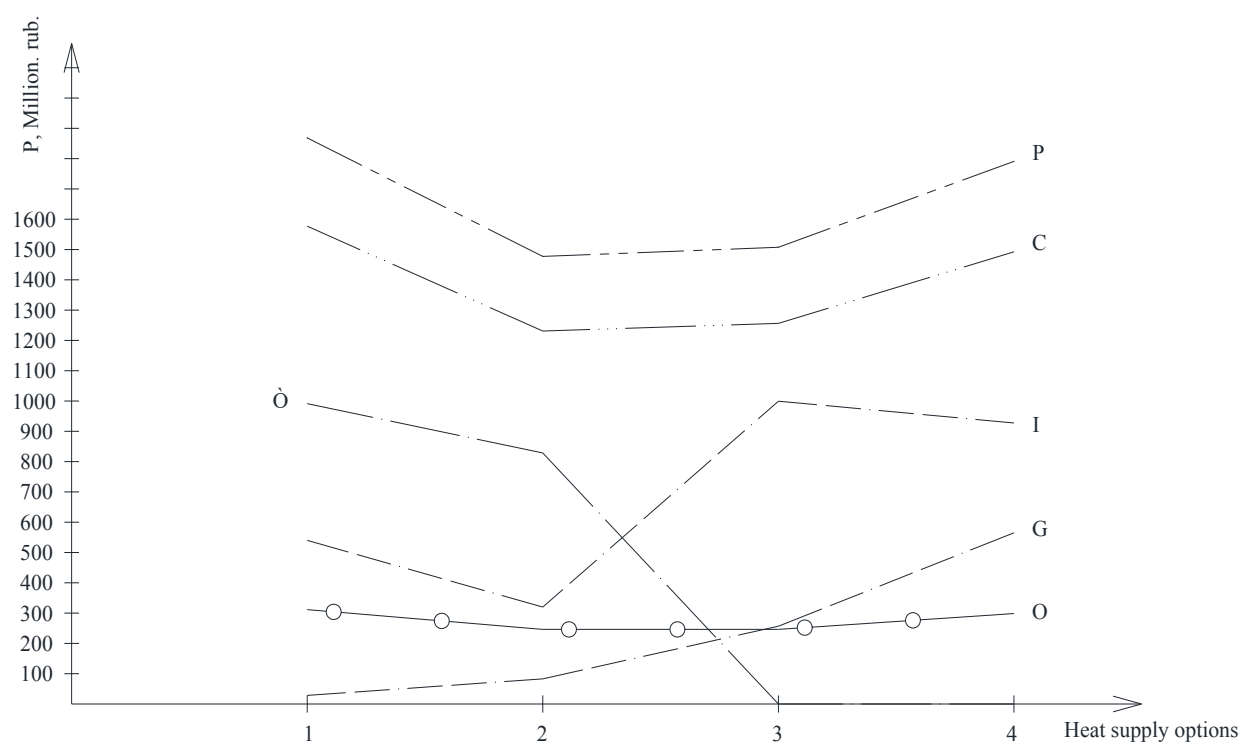

Fig. 2. The schedule of the resulted expenses:

$\mathrm{P}$ - resulted expenses; $\mathrm{K}$ - capital cost; I - capital cost for heat sources; $\mathrm{T}$ - price of heat networks taking into account central heating station/ individual heating station; $\mathrm{G}$ - capital investments in gas network taking into account the price of gas-distributing plant/cabinet-type gas control point

The cost of laying the pipelines of the heat supply system depends on the extent of the heat networks. Consequently, the approach of a heat source that runs on gas to the consumer by installing attached, built-in, roof and individual heat generators will significantly reduce the cost of the system. In addition, statistics show that most of the failures of centralized heating system accrue to heating networks, which means that the reduction of the length of heat networks will increase the reliability of the heat supply system [12].

Since heat supply in Russia is of great social importance, increasing its reliability, quality and economy is the most important task. Any disruptions in providing the population and other consumers with heat have a negative impact on the country's economy and increase social tension.

In the current tense situation, it is necessary to implement resource-saving technologies.

In addition, in order to improve the reliability of the pipelines, pre-insulated pipelines of the non-channel gasket with polyurethane foam insulation in the polyethylene jacket (pipe in the pipe) must be used $[13,14]$.

The essence of the housing and communal services reform should be not the increase in tariffs, but the regulation of the rights and obligations of the consumer and the heat producer. It is necessary to harmonize the legal and regulatory issues and to develop the basis for technological regulation. All conditions of economic attractiveness for investments should be created.

\section{Conclusion}

The analysis of the presented results on the study of heat supply systems makes it possible to choose the optimal option for high-rise buildings, which allow introducing resourcesaving measures and creating conditions for attracting investments. 


\section{References}

1. P.A. Khavanov, N.A. Kharlamova, Ye.B. Solov'yeva. Principal moments in the development of thermal mechanical parts of autonomous heat generating plants. In: Nauchnoe obozrenie. 5, 297-300 (2012).

2. Energy, Technology, Perspectives 2008. Scenarios and strategies to 2050. International energy agency. OECD/IEA (2008).

3. P.A. Khavanov Sources of heat of autonomous heat supply systems (Moscow, 2014).

4. URL: http://www.minstroyrf.ru/ (25.04.2017)

5. Ye.Ye. Novgorodskiy et al. Integrated energy-technological use of gas and protection of the air. Moscow, 368 (1997).

6. URL: http://www.minstroyrf.ru/ (25.04.2017)

7. URL: http://base.garant.ru/ (25.04.2017)

8. D. Butterworth Simplified Methods for Condensation on a Vertical Surface with Vapour Shear. UKAEA Rept. AERE-R9683 (1981).

9. URL: http://www.consultant.ru/ (25.04.2017)

10. V.A. Yakovlev Report at the Government of the Russian Federation Meeting. In Heat Supply News, 6 (2006).

11. L.D. Boguslavskiy, A.A., Simonova M.F. Mitin Economy of heat and gas supply and ventilation. Moscow, 351 (1988).

12. Ye.B. Solov'yeva, A.A. Malysheva. Selection of the optimal trace of the distribution systems of heat and gas supply. In: Agrarian Scientific Journal. 11. 48-50 (2015)

13. N.A., Kharlamova T.S. Pirogova. The process of heat spreading in pipelines as the basis of the "heat wave" method. In. Nauchnoe obozrenie. 10. 53-56 (2015).

14. N.A. Kharlamova, T.S. Pirogova. The "heat wave" method as a method of determining the actual heat losses. In: Nauchnoe obozrenie. 10. 66-69 (2015).

15. A. Ya. Sharipov. Autonomous Heat Supply for Highrise Buildings and Complexes. ABOK. 3 (2016) 